\title{
Evidence for global pressure oscillations in Procyon and a Centauri
}

\author{
B. GXLLY: G. GRXC and E. TOSSAT \\ Departenent d' istrophysique de l' MSP \\ Universite de Hice \\ Parc Palrose \\ F - 06034 HICE CADES
}

Mbstract. Helioseismology has proved to be a powerful tool to probe the intermal structure of the sum. Fith a nev adapted optical resonance spectrophotoneter, an extension has been atterpted to two bright stars, nanely $\alpha$ Centauri $\lambda$ and Procyon. Results obtained fron two observing rums on $\alpha$ Centauri $\lambda$ in Hay 1983 and Hay 1984 at La Silla, and one observing rum on Procyon in February 1984 at Babaii are presented. In both cases, solar-like pressure oscillations have been detected. The complete amalysis is presented, wich leads to deternine essentially five paraneters: the frequency range, the anplitudes, the nean equidistance $\Delta v$, the departure around this equidistance (curvature of the echelle-diagran) and the fine frequency spacing between modes of degree 0 and 2. For Procyon, all results are consistent with theoretical predictions, including excitation of oscillations, mass, radius, and age of the star. For $\alpha$ Centauri, all the results are consistent together and are confirned by the 1984 observations. They suggest that $\alpha$ Cen night be younger than estimated, consistent with a zero age main sequence star.

This is the abstract of a paper recently published in Astronony and Astrophysics. Ve have selected here under sone parts of this paper. For nore detail, it is recomended to refer to this journal.

1. Step by step description of the data amalysis.

a- Low frequency filtering of the data, vith a cut-off at about 0.3 to $0.5 \mathrm{mHz}$, to reduce the atmospheric and instrumental noise.

b- IFT spectrun $P(U)$ of this filtered data, taken as one single tine series, filled vith zeroes wen abservation is not available.

$c-$ Search, in this $P(V)$, of a frequency range whose Fourier analysis provides a cha-function, wutiplied by the vindor function autocorrelation.

d- Calculation of the Fourier transform of the frequency range foum in $c$. This is the squared autocorrelation function of the stellar sigmal filtered in this frequency range.

e- Deternination, along the autocorrelation tine axis, of 
narrov bands containing the cha-function defined in c.

$f-$ Fourier transforn of the complete power spectrun $P(V)$, and restriction of this Fourier transforn to the narros bands defined in c by replacing the complex anplitudes by zeroes between these bands.

g- Inverse Fourier transforn, of the function defined in $f$. showing the discrete pattern searched in $\mathrm{P}(v)$.

h- Fron g. deternimation of the power envelope of the assuned p-node set of dicrete frequencies

i- Echelle-diagran of the filtered power spectrun abtained in g. and neasurement of the erentual currature of the set of nodes on this diagran.

j- Straightening of the echelle-diagran by a polynomial fitting of the curvature.

$k$ - Yertical sun on the echelle-diagran of the unfiltered power spectrun, to search for the eventual frequency separation of modes of degree 0 and 2 (separation impossible on the filtered spectrun).
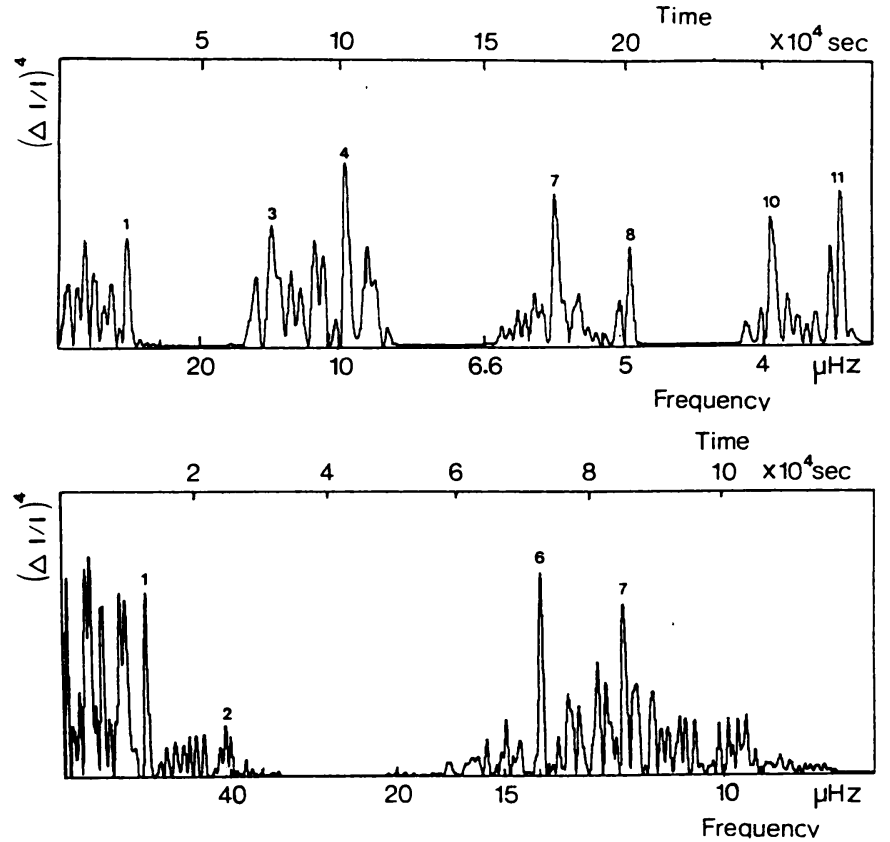

Figure 1. Power spectrun of the 1.17-1.65 $\mathrm{mHz}$ range of the power spectrun of four nights of Procyon data. The autocorrelation of the indow function is clearly visible, as well as a regular pattern of equidistant peaks. The period of the fundanental defines the spacing $\Delta v / 2$ $=39.7 \mu \mathrm{Hz}$.

Figure 2. Sane for the 2.3 $-3.8 \mathrm{aHz}$ range of the power spectrun of 3 nights of $\alpha$ Cen data. In this case, the period of the fundanental defines a spacing of $\Delta v=82.7 \mu \mathrm{Hz}$.

\section{Discussion of results.}

Two recent studies (Christensen-Dalsgaard \& Frandsen, 1983 and Christensen-Dalsgaard, 1984) give us interesting points of comparison between our results and the theoretical predictions. The three min results of these studies are based upon the expected neasurements of the two paraneters $\Delta v$ and $D_{0}$ in the aspototic equation. First it is found that for any zero age min sequence nodel

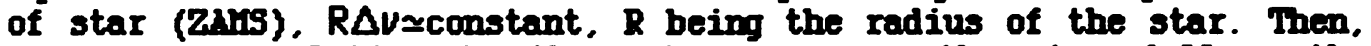
during its evolution in the min sequence, the star follows the homologuous scaling law $R^{2 / 2} \Delta v \simeq$ constant. These lavs can be calibrated against the solar values.

The third result is the diagnostic value of the paraneter $D_{0}$. 
which depends strangly on the gradient of the sound speed near the center. As the star burns its hydrogen, the central nolecular veight increases, consequently the central sound speed and $D_{0}$ decrease vith age.

For Procron, asssuning a mass of 1.5 (in solar mass unit) (Demarque et al, 1985), the $\Delta v$ computed for the zans nodel is $\simeq 95$ $\mu \mathrm{Hz}$

As $R$ increases along the main sequence evolution of the star, $\Delta v$ has to decrease and our value of $79.4 \mu \mathrm{Bz}$ is then consistent vith a star quite much erolved. Fron the calibration vith the solar value. the ZAris sequence of nodel must verify $R \Delta V=145$. This gives for Procron an initial radius of 1.67 . The lav $R^{3 / 2} \Delta v \simeq$ cst gives then a present radius of 1.87 . If sone credit can be given to the non resolution of the $l=0, l=2$ spacing, then $D_{0}<0.6$. This value seens to indicate that Procron is nore evolved than the sum. consistent vith the best nodel conputed by Denarque tho finds a star close to the end of its hydrogen burning min sequence life (Denarque et al. 1985).

Regarding the frequency range and the anplitudes, two different possibilities of excitation have been suggested, manely the $x$-nechaniso (Umo et al. 1979), or the stochastic excitation by interaction with the convection (Goldreich and Keeley,1977). The two suggestions can hardly be distinguished on the sum, because they both predict quite vell the observations. In the case of Procyon, however, they are quite diverging and our result is strongly favouring the stochastic excitation (Christensen-Dalsgaard \& Frandsen,1983). agreeing both vith the frequency range and the expected anplitudes.

Mow, if the general agreenent between theory and observation. is quite satisfactory on Procyon, the results obtained on $\alpha$ Centauri I are really puzzling. Being a nember of the closest multiple star srsten in our neighbourhood, this star has a vell neasured nass of 1.09. Given the precise measurenent of its temperature and of its distance, it has an estimated radius of $1.23 \pm 0.04$ (Blackwell and Shallis,1977). According to Christensen-Dalsgaard \& Frandsen (1983) and as already noticed by Gough (1985), $\Delta v$ should have been $142 \mu \mathrm{Hz}$ when such a star at zero age on the min sequence, its radius should have been 1.03. Vith the neasured value of $165.5 \mu \mathrm{Hz}$, one can deduce from honologuous scaling a present radius of 0.93 . There is an evident contradiction as our result seens to imply that the star has shrunk since its zero age. Eren assuning that this star could be much roumger than the sum, down to zero age, ve have to assune a mass of 1.0 to fit with the theory. There is indeed a general disagreenent about the age of $\alpha$ Centauri (Demarque, 1985: Flamery and Arres,1978; Horel and Baglin,1983) and the idea that that the star is at its zero age evolution stage can perhaps not be rejected. But can the knovledge of the mass be vrong by $9 \%$ ? It must be noted here, that if once again sone credit is given to the measurement of the spacing $l=0, l=2$, then $D_{0} \simeq 2.65$ and the wole figure becones exactly consistent with a zero age solar mass star (Christensen-Dalsgaard, 1984, Fig. 10).

The frequency range, centered around $3 \mathrm{mbz}$, is the only quantity wich agrees quite vell vith predictions. The anplitudes, 5 to 10 tines too large are also puzzling. How if we want to explain 
all the results, the structure of $\alpha$ Centauri has really to be quite different fron expectations, and then a nisatch of oscillations anplitude by such a factor is not too surprising.

\section{Conclusion.}

In contrast to "classical" variable stars, where one or at nost two differents eigemodes are typically found, ChristensenDalsgaand proposes to use the ter seisnology only when a fairly large muber of nodes are observed (Christensen-Dalsgaard,1984). In this respect, one can say that the results presented here, together with those of Hoyes et al. on $\in$ Eridani (1984) and those of Iurtz et al. on Ap stars (1983) wark the real birth of stellar seisnology. It is obvious that the observation is extrenely nore difficult in this case than it is on the sum. The present results are at the linit of the noise lerel, and one camnot completely exclude the possibility of a nisinterpretation, in spite of the care of the analysis.

Nor cones the question: Hor vill it be possible to do mach better in the the nearest possible future. This question has already be debated in serreral recent neetings or workshops (for example Ifeudon 1984. San Diego 1984, Canbridge 1985). 111 these debates lead us to have the following feeling, wich vill be our conclusion of this short presentation.

Te definitely have the optinistic hope that trough this open door of stellar seisnology, mang results vill cone out in the next fer rears, providing a real new dinension to the tests of stellar erolution theory. And the perhaps less enthousiastic point of viev that eren if in principle, stellar observations can be as precise (or eren nore precise) than solar observations, it vill take sone tine before that becones a reality.

\section{References.}

Blackwell D.E. Shallis H. J. :1977, Hon. Hot. R. Lstr. Soc. .180,177

Christensen-Dalsgaard J. Frandsen S. :1983, Solar Phys. .82, 469

Christensen-Dalsgaard J.:1984,Space research prospects in stellar activity and variability (eds. $\lambda$. fangeney and F.Praderie,Paris Obs press),p. 11

Denarque p.et al.:1985,Proceedings of the Forkshop on the Seisnology of the Sun and Other Stars,Cambridge,1985, Reidel.

Elamery. B.P. and AYres, T.R. : 1978 Lstrophys. j. 221, 175

Fossat E. :1984 b. Space Research Prospects in Stellar Activity and Pariability (eds. M. Hangeney and F.Praderie,Paris Obs Press)p. 77

Goldreich P. Keeley D.A. :1977, Astrophys.J. .212,243

Gough D. :1985, Pature, 314.14

Kurtz,D. . and Seeman, J.:1983, Hon. Hot.R. Astr. Soc. . 205, 11

Horel P.\& Baglin A.:1983, Commication aux For journces de I' abservatoire de Strasbourg.

Hoyes R. I. Baliumas S.L. Belserene R. Duncan D.I. Horne J. \& Fidrow L. :1984, Astrophys. J. .265,L23-L26

Uimo I. Osaki Y. indo H. \& Shibahashi H.:1979,Lonradial Oscillations of Stars (Unirersity of Tokio Press) 